\title{
Demineralization prevention with a new antibacterial restorative composite containing QASi nanoparticles: an in situ study
}

\author{
Peter Rechmann ${ }^{1}$ (D) $\cdot$ Charles Q. Le ${ }^{1} \cdot$ Benjamin W. Chaffee ${ }^{1} \cdot$ Beate M.T. Rechmann ${ }^{1}$ \\ Received: 30 August 2020 / Accepted: 9 February 2021 / Published online: 19 February 2021 \\ (C) This is a U.S. government work and not under copyright protection in the U.S.; foreign copyright protection may apply 2021
}

\begin{abstract}
Objectives To investigate whether a newly developed dental composite with quaternary ammonium silica dioxide (QASi) nanoparticles incorporated with other fillers into the restorative material demonstrates antibacterial activity by reducing enamel demineralization in an in situ gap model.

Materials and methods Twenty subjects wearing a lower removable partial denture (RPD) with acrylic flanges on both sides of the mouth were recruited into the 4-week in situ study. The gap model consisted of an enamel slab placed next to a composite, separated by a 38- $\mu \mathrm{m}$ space. In the split-mouth design on one side of the RPD, the composite was the Nobio Infinix composite (Nobio Ltd., Kadima, Israel), and the contralateral side used a control composite. Each participant received enamel slabs from one tooth. The gap model was recessed into the RPD buccal flange, allowing microbial plaque to accumulate within the gap. After 4 weeks of continuous wearing, decalcification ( $\Delta \mathrm{Z}$ mineral loss) of the enamel slabs adjacent to the gap was determined by crosssectional microhardness testing in the laboratory.

Results The $\Delta \mathrm{Z}$ for the antibacterial composite test side was $235 \pm 354$ (mean \pm standard deviation [SD]; data reported from 17 participants) and statistically significantly lower compared to $\Delta \mathrm{Z}$ of the control side $(774 \pm 556$; mean $\pm \mathrm{SD}$ ) (paired t-test, $P<0.0001$; mean of test minus control -539 ( $\mathrm{SD}=392), 95 \%$ confidence interval of difference: $-741,-338$ ).

Conclusions This in situ clinical study showed that composites with QASi antibacterial particles significantly reduced demineralization in enamel adjacent to a 38 - $\mu \mathrm{m}$ gap over a 4-week period in comparison to a conventional composite.

Clinical relevance Composites with QASi nanoparticle technology have the potential to reduce the occurrence of secondary caries. Trial registration ClinicalTrials.gov \#NCT04059250
\end{abstract}

Keywords Secondary caries - Enamel demineralization - Antibacterial composite $\cdot$ Quaternary ammonium silica dioxide particles $\cdot$ In situ clinical trial $\cdot$ Gap model

\section{Introduction}

Secondary caries, also called recurrent caries, is considered as a lesion that develops adjacent to a restoration $[1,2]$. Up to twothirds of all restorative dentistry involves the replacement of failed restorations [3-5]. Acid-producing cariogenic bacteria located at the margin of the filling forming an outer caries lesion or located inside a gap between the filling and enamel producing an inner wall lesion are major reasons for recurrent caries. These gap

Peter Rechmann

Peter.Rechmann@ucsf.edu

1 Department of Preventive and Restorative Dental Sciences, School of Dentistry, University of California, San Francisco, 707 Parnassus Avenue, San Francisco, CA 94143, USA formations at the interface between the tooth and composite may occur due to shrinkage during polymerization of the composite $[3,6,7]$. During the life of a restoration, an unstable bonding of the composite to dentin may also be responsible for a gap formation. These gaps were measured and found to be 15-20 $\mu \mathrm{m}$ [8]. Due to the clinical difficulty to control saliva, gingival fluid, or blood entry at the approximal gingival margins during placing a composite restoration, the gap may be even larger. Indeed, bacterial penetration and secondary caries around composite restorations were demonstrated in vitro and in vivo with gap sizes of 20-50 $\mu \mathrm{m}$ and higher [9].

To prevent secondary caries, the influence of dental materials to inhibit caries development has been tested. The caries inhibition effect of glass ionomer cement [10-12] and the effect of glutaraldehyde on secondary caries [13] have been evaluated. Furthermore, fluoridated composites might reduce or inhibit secondary caries [13]. 
A recently developed sol-gel-derived bioactive glass ceramic containing silver ions (Ag-BG) in the resin composite induced remineralization and showed antibacterial properties [14] without significantly reduced total bond strength [15]. In addition, several groups are researching the possibility of using composite restorative materials that incorporate other antibacterial agents to overcome the described deficiencies [15-20]. Consequently, composite resin hybrid layer degradation as major challenges encountered in long-term resin-dentin bond stability might be reduced.

As a link between resin and dentin, adhesives that possess both antimicrobial and anti-proteolytic activities can eliminate bacteria-induced secondary caries and prevent hybrid layers from degradation. Recently, a study reported that a new quaternary ammonium methacryloxy silane (QAMS) prepared from sol-gel chemistry was incorporated into experimental adhesives to examine its antimicrobial effect and antiproteolytic potential [21].

The potential for caries activity due to bacteria around the filling may be interrupted by quaternary ammonium silica dioxide (QASi) particles [22] incorporated in a composite at $1.2 \%$ (by weight). These composites incorporate non-leaching antibacterial agents $[18,16,23]$ and may inhibit the development of new active caries around freshly placed fillings. QASi particles are synthesized to form a high concentration of antimicrobial groups $[23,24]$ that are covalently bound onto a carrier core, such as silica [22]. The resulting micro- or nano-size QASi particles are mixed with other fillers of the dental composite material during manufacturing and are evenly distributed throughout the composite. Following in situ placement of the filling material and light-initiated polymerization, QASi particles are permanently retained in the final dental restoration. Laboratory studies have shown that the quaternary ammonium silica particles are potent antibacterial agents, do not leach out in contrast to other antimicrobials or caries-preventive active substances, inhibit the breakdown of the composite, and maintain antibacterial activity over time [16-19, 23-25].

Consequently, composites featuring QASi nanoparticles have the potential to significantly reduce the occurrence of secondary caries [19]. The overall objective of this clinical study was to investigate whether a composite with QASi nanoparticles would reduce demineralization in enamel located adjacent to an artificial gap in comparison to a nonantibacterial control composite in a 4-week, split-mouth in situ experimental study.

\section{Materials and methods}

\section{Participants}

This study was performed between February 2019 and March 2020 at the University of California, San Francisco
(UCSF) School of Dentistry. UCSF Institutional Review Board (IRB) approval was obtained (IRB \#18-26344), and the study was registered with the US National Institute of Health (ClinicalTrials.gov Identifier: NCT04059250). Information about the study was provided to participants in a standardized manner via an informational leaflet and demonstration aids.

Prior to enrolling into the study, an independent dental examiner, not otherwise involved in the study, conducted a clinical exam to assess caries status and to determine any treatment needs of the potential participant. Medical history and definitive dental history were evaluated, and an intraoral examination and a review of intraoral radiographs were performed.

Inclusion criteria for the study were a participant (a) aged between 18 and 80 years, (b) having at least eight natural teeth remaining and having dental caries in the last 3 years, (c) wearing a lower partial denture (with replaced teeth on both sides of the mouth), (d) willing to wear his or her RPD during day and night, (e) who had to be healthy and in good current oral health with no active caries or periodontal disease (but with a history of caries leading to fillings or extractions of teeth in the past), (f) who had saliva flow within the normal range (stimulated saliva flow rate of greater than $0.7 \mathrm{ml} /$ minute), (g) with no antibiotic medications for the last 3 months, (h) who had resided in San Francisco or other nearby local communities with water fluoridation, and (i) who signed the "Authorization for Release of Personal Health Information and Use of Personally Unidentified Study Data for Research" form. There were no gender restrictions.

Exclusion criteria included, but were not limited to, subjects (a) suffering from systemic diseases, (b) with a significant past or medical history with conditions that may affect oral health (i.e., diabetes, HIV, heart conditions that require antibiotic prophylaxis), (c) using medications that may affect the oral flora or salivary flow (e.g., antibiotic use in the past 3 months, drugs associated with dry mouth/xerostomia), (d) using a $5000 \mathrm{ppm}$ fluoride toothpaste in the last 6 months, (e) using chlorhexidine or any other antimicrobials (cetylpyridinium) in the last 6 months, and (g) showing evidence of extremely poor oral hygiene. Patients with extremely poor oral hygiene, as evident by visible heavy plaque deposits on all remaining teeth, were excluded due to an extreme chance of a further raised caries risk.

From the UCSF School of Dentistry clinics, 115 potential participants were screened between February 28, 2019 and February 5, 2020, and 30 were eligible and were invited to participate. Finally, a total of 25 agreed to participate and were enrolled into the study ( 5 for the pilot study and 20 for the main study). Participants who met the selection criteria provided written informed consent. 


\section{Randomization}

Participants had RPD buccal flange sides (right or left) randomly assigned to the test (antibacterial active composite) or control (non-antibacterial composite) group. The randomization list was created by a random number generator (QuickCalcs Online Random Numbers by GraphPad Software, Inc., CA). The randomization list was kept locked, and side assignments were kept in separate, closed, opaque, sequentially numbered envelopes. Only after a participant had been enrolled, the nextin-line group assignment was revealed.

The participant was blinded to the active treatment/control allocation side. The study investigator and the study coordinator (BR) were not blinded to the group assignment. (For blinding of the laboratory person doing the microhardness testing, please see the below section "Blinding in the laboratory.") The randomization list remained secured until the completion of all data collection in the main study.

\section{Study procedure}

\section{The gap model}

The gap model was prepared in the laboratory. The gap model is a small acrylic "bathtub-shaped" concave form, which carries the enamel slab, the composite, and the gap (Fig. 1). The gap model was a representation of the conditions leading to an inner surface caries lesion, a typical secondary caries wall lesion. Two of those forms were integrated into the flanges of an RPD (Fig. 2), on one side with the active antibacterial test composite (Nobio Infinix, Nobio Ltd., Kadima, Israel) and on the opposite side with the control composite (Dentsply EsthetX HD, Dentsply Sirona Ltd., Milford DE).

Figure 1a shows a schematic with the enamel slab, the composite, and the gap in-between. For each participant, enamel slabs originated from one donor tooth only to reduce variation in intra-participant conditions. The gap, which simulated a gap around a placed composite filling, was created by inserting a matrix band (Tofflemire Matrix Band, No.1, thickness 0.0015, Patterson Dental Supply, Saint Paul, MN) next to the enamel as a divider, prior to placing the composite resin in increments according to manufacturers' instructions. To achieve a uniform pressure against the matrix band, the increment height of the composite was chosen at roughly $1 \mathrm{~mm}$ (manufacturer instructions allow for 2-mm increments). The composite was light-cured for $15 \mathrm{~s}$ per increment (manufacturer instructions require a minimum of $10 \mathrm{~s}$ ). The composites were light-cured with a Satelec ${ }^{\circledR}$ Mini LED curing light (Acteon North America, Mount Laurel, NJ). The light output of the curing light was verified with a curing radiometer; the Acteon Satelec Mini LED curing light gave consistently an output of $>1250 \mathrm{~mW} / \mathrm{cm}^{2}$ throughout the study. The matrix band had a thickness of $38 \mu \mathrm{m}$, confirmed by repeated measurements, resulting in a consistent gap width throughout the study. The produced gap was not measured after the composites were cured. The matrix band did not touch the floor of the "bathtub-shaped" concave form (Fig. 1a). This allowed a small amount of composite to reach the enamel, which prevented bending of the form. No changes in gap width occurred during integration of the gap model into the RPD flanges. The gap model with the enamel slabs and composites was recessed into the flange (shown in Fig. 2), mounted with light-cured acrylic composite resin, allowing microbial plaque to accumulate in the gap.

Since the pilot part of the study showed that we achieved sufficient caries wall lesions in a 4-week study period, we did not request from our participants to use additional extraoral sucrose dipping or rinsing to enhance the caries process.

\section{Source of teeth}

We used teeth that were previously extracted for clinical reasons (not research purposes) in the dental clinics of the UCSF School of Dentistry. Correct collecting, storing, and handling of human teeth under biosafety aspects is covered under our BUA approval (BUA 2308-BU-01-INC) and a UCSF IRB exempt approval for collecting extracted teeth.

\section{Test samples}

Extracted teeth (molars) were stored in $0.1 \%$ thymol solution in deionized water and sterilized with gamma irradiation (Cs 137) at a dose above $173 \mathrm{krad}$ overnight. Following sterilization, the collection media was replaced with fresh deionized water and thymol. The tooth roots were removed below the cemento-enamel junction, and then, the remaining dental crowns were cut in halves, with the cut going from mesial to distal, leaving a buccal and a lingual half (Fig. 2).

At least 50 enamel samples from 25 extracted molars were prepared from the buccal halves of the dental crowns. One buccal half was cut into two pieces; those two pieces were collected in the same vial to ensure that later on for each single participant enamel slabs originated from one tooth. The test surfaces were cleaned, and the surface was flattened by serial polishing $(240,600$, and 1200 grit polishing paper, sterilized). The smear layer was removed by sonication. Two standard slabs approximately $3 \times 2.5 \times 2.5 \mathrm{~mm}$ were cut from each tooth crown. Before placing the enamel slabs into the gap model, all surfaces but the gap side surface were covered with acid-resistant nail varnish (Fig. 2). All gap models were sterilized with gamma irradiation before use in the mouth.

\section{Testing and analysis methods}

The analysis method used was cross-sectional microhardness testing by detailed "scatter pattern" of indentation. Figure 3 
Fig. 1 The gap model. a Schematic of the gap model with the enamel slab on the left, the composite on the right, and the defined gap between the composite and the enamel slab, created by a $38-\mu$ m-thin matrix band inserted during the composite placement, all prepared inside an acrylic bathtub-like form; red acid-resistant nail varnish covering the top of the enamel slab; "A - arrow" pointing at the level inside the depth of the gap where cross-sectional hardness testing in the laboratory will occur after wear time in the mouth; "W" marking the wall lesion enamel surface. b Enamel slab removed from the acrylic form and ready for embedding in epoxy resin. c Enamel slab ground down 600 to $800 \mu \mathrm{m}$ from the top surface, exposing flat surface showing crosssectional microhardness indentations
Fig. 2 Schematics demonstrating the process from cutting the tooth up to integrating the gap models in the RPD denture flanges, with a cutting off the dental crown at the cemento-enamel junction; b cutting the buccal crown surface into 2 identical slabs; c example of a gap model with the enamel slab, the composite, and the defined gap created by inserting a $38-\mu \mathrm{m}$-thin Tofflemire matrix band next to the enamel slab during the incremental placing of the composite at the opposite side of the enamel, in order to simulate a gap "around" a composite filling; d a gap model in front of the right flange and acrylic removed from the flange allowing the gap model to fit inside the flange; e gap model placed inside the flange, firmly locked in the flange using a composite; and $\mathbf{f}$ overview of the lower partial denture with one gap model integrated in the right denture flange and the other in the left flange (not visible in this picture)
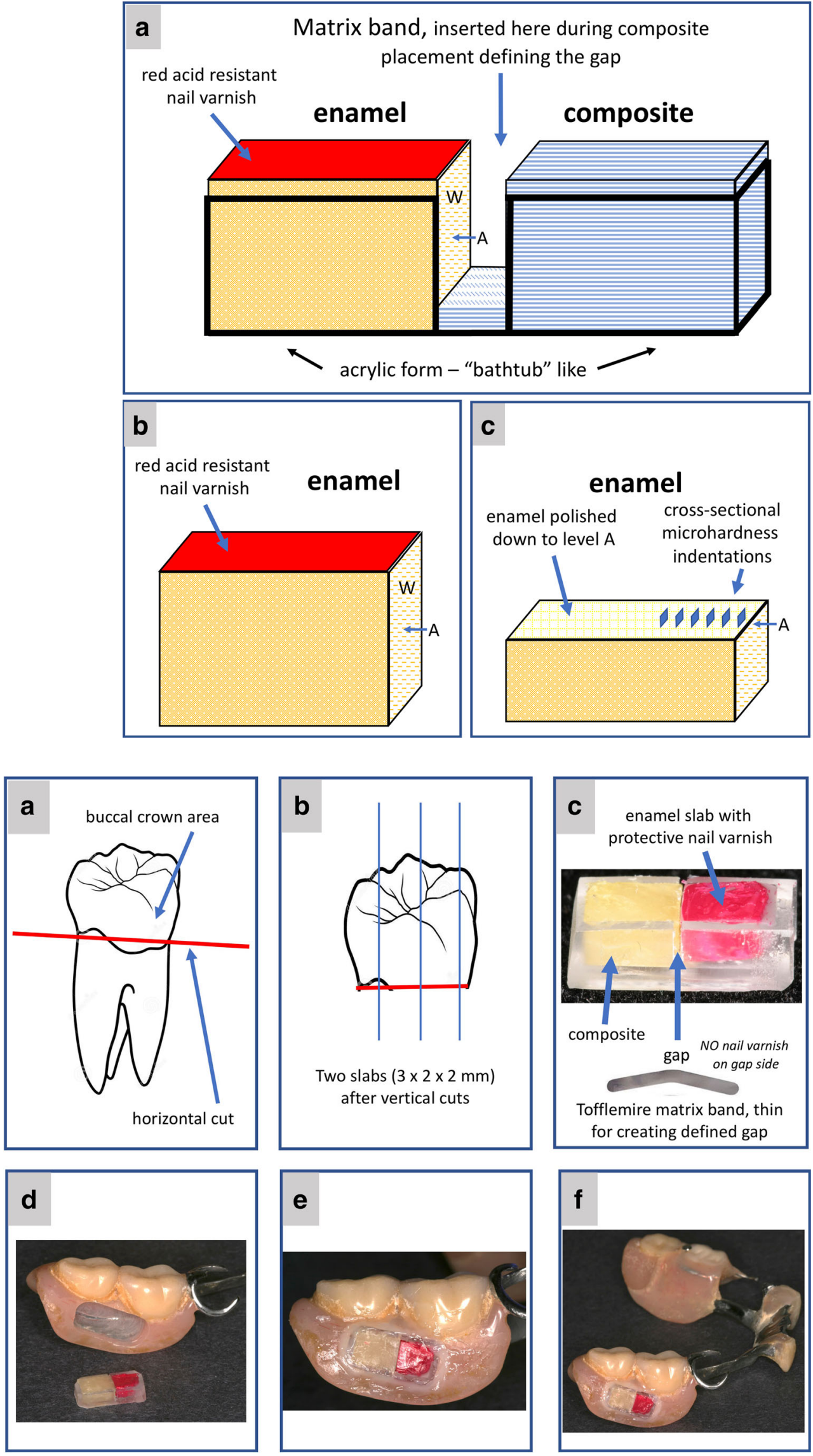
shows the Knoop hardness indent placement for the crosssectional microhardness testing in a schematic graph with typical positions of the indents in a scatter pattern. The indents are placed at the cross-sectional surface, which is perpendicular to the wall lesion (W) caused by the microbial plaque in the gap. At the end of 4 weeks in situ, the treatment and the control slabs were removed from the RPD flanges. The defects in the buccal flanges were restored with self-curing acrylic resin. Both slabs were embedded and used for microhardness testing as described below.

\section{Cross-sectional microhardness measurements: level of cross-section related to depth inside the gap}

After the 4-week wearing period, the enamel slabs were removed from the acrylic form and were embedded in epoxy resin (Allied High Tech Products, Compton, CA), leaving the top flat section surface uncovered from the epoxy resin. This is the surface facing the oral cavity in the gap model (covered with red acid-resistant nail varnish (with respect to secondary caries, this surface would have been the surface developing an "outer caries lesion") (Fig. 1a and 1b). In order to perform cross-sectional microhardness testing related to caries induced from bacteria in the gap, the samples were removed from the acrylic form (Fig. 1b). Then, after embedding in epoxy resin, the samples were ground down 600 to $800 \mu \mathrm{m}$ from the top surface (Fig. 1c), which had faced the oral cavity covered with acid-resistant nail varnish, to the level marked with the arrow "A" on the gap facing caries wall lesion "W." Consequently, the mineral loss was determined roughly at a level of 600 to $800 \mu \mathrm{m}$ depth inside the gap. After serial polishing (240 and 600 grit silicon carbide polishing paper followed by 6-, 3-, and $1-\mu \mathrm{m}$ diamond polishing suspension), the exposed flat surface was indented (25-g weight, 10 -s indentation duration) to test for microhardness cross-sectionally using a Buehler microhardness tester (Buehler, Germany) and microscopic examination. The first indent was placed $15 \mu \mathrm{m}$ from the resin interface (Fig. 3). Subsequent indents were placed in $5-\mu \mathrm{m}$ increments to a depth of $50 \mu \mathrm{m}$ in the underlying enamel; implementing a V-shaped pattern prevented interaction and interference between the indents. Additional indents were placed at $25-\mu \mathrm{m}$ intervals into underlying sound enamel following a straight line perpendicular to the outer surface to a depth of $300 \mu \mathrm{m}$ (Fig. 3). Figure 3 at the bottom shows a light microscopical picture of typical microhardness indents placed starting at $15 \mu \mathrm{m}$ under the enamel surface. The volume percent mineral for each indent was normalized based on sound underlying enamel $(100-300 \mu \mathrm{m})$ set at $85 \%$. This is an internal calibration of the measurements that exists within the $\Delta Z$ formula. It allows normalization of the microhardness data on

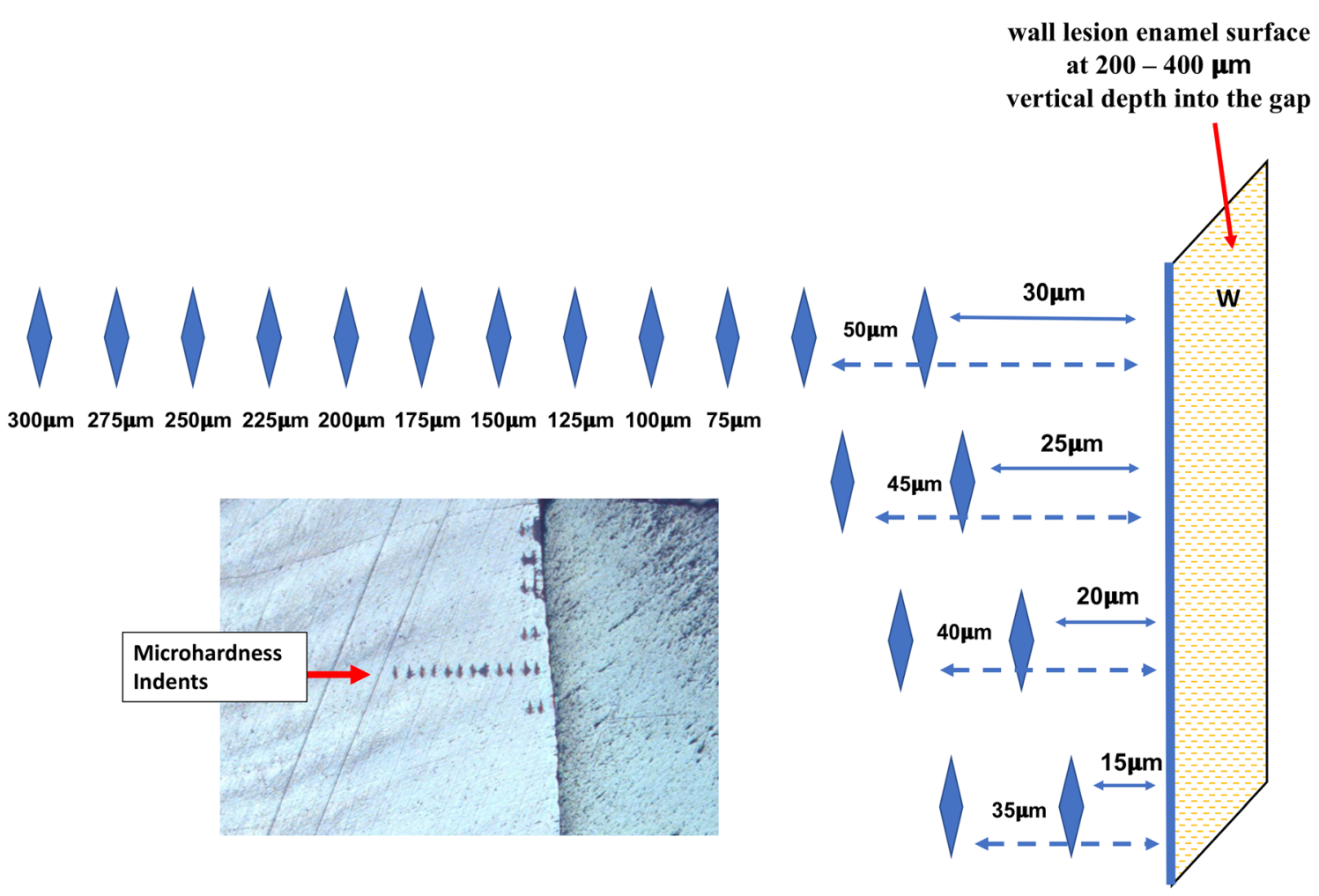

Fig. 3 Knoop hardness indent placement for cross-sectional microhardness testing in a schematic graph with typical positions of the indents in a scatter pattern, with "W" marking the wall lesion enamel surface; indents occur on the cross-sectional surface (perpendicular to the wall lesion caused by the microbial plaque in the gap); the light microscopical picture shows typical microhardness indents placed, starting at an area $15 \mu \mathrm{m}$ under the enamel surface 
a per-tooth basis, such that tooth-to-tooth variability is eliminated $[11,26]$. All data were verified for reproducibility of the measurement method and quality assurance by repeating any outlier measurements. Measurement of indentation lengths was performed with the aid of Image-Pro Plus 4.0 software (Media Cybernetics, Inc., Rockville, MD), which was used for capturing and measuring the image through a microscope (Olympus BX50, Melville, NY) at 500× magnification.

The overall relative mineral loss $(\Delta \mathrm{Z})$ for each sample was calculated by creating a hardness profile curve by plotting normalized volume percent mineral against distance from the outer enamel surface. The area under the curve that represents $\Delta \mathrm{Z}(\mu \mathrm{m} \times$ vol $\%$ mineral $)$ was calculated using Simpson's integration rule. The individual $\Delta Z$ values for each lesion in each group were combined to give a mean $\Delta Z$ and standard deviation for each of the groups (test, control).

\section{Blinding in the laboratory}

The technician measuring the indentation lengths was blinded to the group assignment for the test and control group. Enamel slabs were delivered to the laboratory technician in numbercoded vials. The study coordinator had an appropriate list for coding and decoding.

\section{Wash-out phase, clinical}

Participants started their study involvement with a 2-week washout period using over-the-counter (OTC) 1100 ppm Ftoothpaste to brush their teeth (there was no professional tooth cleaning at the start of the study in order to not interrupt biofilm activities). The toothpaste (Crest Cavity Protection, Procter \& Gamble, Cincinnati, $\mathrm{OH}$ ) and toothbrushes (Colgate Plus soft, Colgate-Palmolive, Morristown, NJ) were provided to each participant.

\section{Pilot study}

A pilot study was conducted, in which 5 participants (4 males, 1 female; average age $60.1 \pm 16.8$ years; 1 Hispanic/Latinx, 3 non-Hispanic White, 1 African American) were selected after a 2-week washout phase to wear their RPDs with gap models with test and control composites for 4 weeks (for more details, see "Main study phase," below). Data were used to determine whether a wearing period of 4 weeks was enough to achieve sufficient demineralization of the enamel slab (see sample size and power calculation below). The 4-week test period proved to be sufficient. Consequently, the obtained data were used to perform a sample size calculation for the main study, and the same protocol was utilized for the main study.

\section{Main study}

After the 2-week washout period, the gap models with slabs and composites were mounted into the RPD flanges, and the participants wore their RPD for 4 weeks. The participants were instructed to brush their teeth twice daily for $1 \mathrm{~min}$ with the provided OTC $1100 \mathrm{ppm}$ fluoride toothpaste. The participants were asked to remove the RPDs from the mouth before brushing their teeth. They were asked to brush the inside of the RPD and the denture teeth (without any toothpaste) but not the area with the slabs.

The study coordinator contacted by telephone the households approximately once a week to assist with compliance. After 4 weeks, the gap models were removed, and the enamel samples were prepared for the laboratory cross-sectional microhardness testing to determine the $\Delta \mathrm{Z}$ mineral loss.

\section{Outcome measures}

The primary outcome measure was the reduction in enamel mineral loss $\Delta \mathrm{Z}$ in the antibacterial active test composite group compared to the control group.

\section{Power calculation}

After having performed a pilot study with 5 participants, we calculated the sample size for paired differences based on the $\Delta \mathrm{Z}$ mineral loss results obtained from these 5 participants. The calculation took into account the mean difference between pairs and the standard deviation of the differences. Based on these data, we assumed that the study would require a sample size of 17 (number of pairs - 17 participants, each wearing test and control samples) to achieve a power of $80 \%$ and a level of significance of $5 \%$ (two sided), for detecting a mean of the $\Delta \mathrm{Z}$ differences of 383 between pairs, assuming the standard deviation of the differences to be $\Delta \mathrm{Z} 507$. To account for loss to follow-up, we planned to recruit 20 participants into the study.

\section{Statistical methods}

The main outcome, reduction in enamel mineral loss $\Delta \mathrm{Z}$, was compared between the intervention and control enamel slabs using the two-tailed, paired t-test for significance at $P<0.05$. Additionally, a mixed-effects linear regression model was fitted for enamel mineral loss $\Delta \mathrm{Z}$ with a random intercept for participant and fixed effects for intervention (antibacterial active test composite vs. control), gender (female vs. male), denture age (newer RPD vs. older RPD [with newer RPD defined as received in the last 4 weeks]), duration of wearing the gap model with the slabs in the mouth (>28 days vs. 28 days or less), and RPD flange side with test composite (left vs. right). Model coefficients were considered statistically significant if $95 \%$ confidence intervals excluded the null value (i.e., 0 difference in enamel mineral loss $\Delta Z$ ). Analyses were completed using Stata 16.1 (StataCorp, College Station, TX). 
Table 1 Characteristics of the study population

\begin{tabular}{lll}
\hline & $\begin{array}{l}\text { Enrolled } \\
(N=20)\end{array}$ & $\begin{array}{l}\text { Follow-up participants } \\
(N=17)\end{array}$ \\
\hline $\begin{array}{l}\text { Baseline age, mean (SD) } \\
\text { Sex, n (\%) }\end{array}$ & $64.6(13.7)$ & $63.8(13.5)$ \\
Female & $7(35)$ & $5(29)$ \\
Male & $13(65)$ & $12(71)$ \\
Race/ethnicity, n (\%) & & $5(29)$ \\
African American & $2(10)$ & $2(12)$ \\
Asian & $2(10)$ & $1(6)$ \\
Hispanic/Latinx & $9(45)$ & $8(47)$ \\
Non-Hispanic White & $1(5)$ & $1(6)$ \\
Others & & $11(65)$ \\
Test material quadrant, $n(\%)$ & $13(65)$ & $6(35)$ \\
Right flange & $7(35)$ & $27.8(1.2)$ \\
Left flange & $27.9(1.3)$ & \\
Days of wearing in situ gap model, mean (SD) & & \\
\hline
\end{tabular}

\section{Results}

Mean participant age at baseline was $64.6 \pm 13.7$ years (mean \pm standard deviation [SD]) (range: 33.7 to 80.98 ). From the enrolled, 13 participants were male, and 7 were female. One participant was Native American, 2 participant identified as Hispanic/Latinx, 9 non-Hispanic White, 6 African American, and 2 Asian (Table 1). Since all participants fulfilled the inclusion criteria for this study with experiencing dental caries in the last 3 years, they were assessed as having a high caries risk, according to the Caries Management by Risk Assessment (CAMBRA) rules [27, 28].

Eleven participants provided older preexisting removable partial dentures (RPDs), while 9 had just received a new removable partial denture in the last 3 to 4 weeks in the dental clinics. The random assignment of placing the test or control composite into the right or left RPD flange resulted in 7 times of allocation of the test composite into the left and 13 times into the right RPD flange (Table 1). During the study period, participants were wearing the in situ gap models for an average of $27.9 \pm 1.3($ mean $\pm \mathrm{SD})$ days. The targeted 4-week in situ wearing time was rather accurately achieved. No adverse events or side effects were reported.

\section{Overall average $\Delta \mathrm{Z}$ mineral loss}

The results include data from only 17 study participants (Table 1). One study participant did not follow the instructions to wear the RPD day and night and was wearing the RPD for less than $12 \mathrm{~h}$ on multiple days. Data from this participant were not included. Due to COVID-19 "Shelter-in-Place" order, $\Delta \mathrm{Z}$ values for two participants could not be evaluated.
The average mineral loss $\Delta \mathrm{Z}(\mathrm{vol} \% \times \mu \mathrm{m})$ of an enamel slab on one side of an artificial gap facing the control composite was $774 \pm 556$ (mean \pm standard deviation [SD]). In contrast, when the antibacterial test composite was located on one side of the artificial gap, the gap opposing enamel slabs showed in average a $\Delta Z$ of $235 \pm 354$ (mean $\pm S D$ ), which was significantly less mineral loss. This difference in average mineral loss between control and test sides was statistically significant (paired t-test, $P<0.0001$; mean of test slabs minus control slabs -539 , SD 392, 95\% CI: $-741,-338)$.

\section{Mixed-effects linear regression}

In the mixed-effects regression model (Table 2), the intervention test composite was similarly associated with decreased enamel demineralization compared to the control (difference in $\Delta \mathrm{Z}:-535 ; 95 \%$ CI: $-712,-357$ ). Additional participants' factors associated with greater demineralization were placement of the gap model with the antibacterial active group in the flange of a newer denture (difference in $\Delta \mathrm{Z}: 386 ; 95 \% \mathrm{CI}$ : $49,724)$ and duration between baseline and assessment $>28$ days (difference in $\Delta Z: 394 ; 95 \%$ CI: 10, 779). Participant gender and placement of the gap model with the antibacterial active group in the right or left denture flange were not statistically significantly associated with enamel mineral loss $\Delta \mathrm{Z}$.

\section{$\Delta Z$ Mineral loss: individual and average difference}

Figure 4 shows the $\Delta \mathrm{Z}$ mineral loss for the control and for the antibacterial active test composite side presented for all 17 study participants as individuals. For the test side, the $\Delta \mathrm{Z}$ mineral loss ranged from -268 to 862 , while the values for the controls were assessed between $\Delta \mathrm{Z} 213$ and 2081. The 
Table 2 Enamel demineralization ( $\Delta \mathrm{Z}$ mineral loss): mixed-effects regression model

\begin{tabular}{lll}
$\begin{array}{l}\text { Adjusted difference } \\
\text { in mineral loss } \\
(\text { volume } \% \times \mu \mathrm{m})\end{array}$ & $95 \%$ confidence interval & $P$-value \\
& $(-712,-357)$ & $<0.001$ \\
-535 & $(-65,675)$ & 0.11 \\
305 & $(49,724)$ & 0.03 \\
386 & $(10,779)$ & 0.04 \\
77 & $(-100,254)$ & 0.40 \\
\hline
\end{tabular}

Treatment assignment:

Test composite (reference: control)

Gender:

Female (reference: male)

Denture age:

$<4$ weeks (reference: $>4$ weeks)

Time since baseline:

29-30 days (reference: 26-28 days)

Placement on denture

Left flange (reference: right flange)

Model includes 34 observations from 17 participants in a split-mouth design with a random intercept for participant (chi-bar $P$-value: 0.01 ) and fixed-effects for the main terms graph demonstrates that for all individual cases, the $\Delta \mathrm{Z}$ mineral loss for the test side was lower than the mineral loss observed for the control side.

\section{Discussion}

In research, the use of experimental intraoral models dealing with caries prevention has increased over time. The most realistic experimental model is the in vivo model that uses living teeth followed by the in situ model using specimens with natural surfaces held in the mouth during the experimental period [29]. In situ models have the potential to study both fundamental aspects of the caries process and more applied research problems in caries prevention in human subjects without actually causing caries in the natural dentition [30]. In situ models are able to produce statistically significant differences to compare the use of different fluoride toothpastes and controls [31-37], fluoride mouth rinses [38], antimicrobial releasing agents [39], varnishes [40], and other fluoride releasing products [41-44]. In situ studies have also evaluated the effect of biomaterials and food on demineralization and remineralization $[45,46]$.

Regarding study design, numerous in situ models have been described [30]. Orthodontic brackets have been used as a plaque trap on enamel $[11,47]$, as well as a carrier for slabs [48]. Interproximal models [49] with partial dentures for testing the effect of fluoride on enamel have also been used. Recently, a systematic review about simulation of secondary caries in in situ models reported that three main groups of in situ models could be identified by sample placement [50]. Sixty-eight percent of these models placed samples palatally in the upper jaw. The lower jaw model could be divided into the buccal $(26 \%)$ and approximal areas $(6 \%)$. The average lesion progression in enamel per day was calculated at $4.3 \pm$
$2.8 \mu \mathrm{m}$ (range 1.1-8.8 $\mu \mathrm{m} /$ day) [50]. Studies conducted with palatal models showed caries progression rates 2-5 times higher than the estimated clinical progression rates [50]. Fluoride-containing toothpastes were used in $48 \%$ of the studies, and $42 \%$ had their volunteers use fluoride-free toothpaste. Studies showing a high caries progression rate in all palatal models, using a mesh for plaque promotion above the samples, and experiment durations were only 2 weeks. It was also observed that samples with a natural surface, not polished flat, slowed down initial lesion formation [50].

Secondary caries is described to consist of an outer and an inner lesion or wall lesion [51, 52]. The outer lesion is caused by the primary caries attack on the tooth surface and appears histologically as a primary caries lesion. The wall lesion, however, is the consequence of micro-leakage and subsequently intruding cariogenic bacteria [52]. Thus, the wall lesion is the result of bacteria, fluids, and hydrogen ions diffusing into the gap between restoration and cavity wall [53, 54].

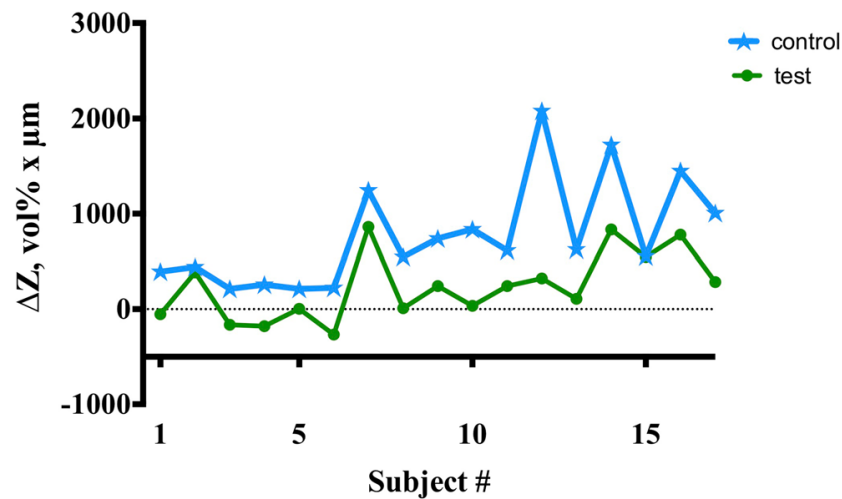

Fig. 4 Individual $\Delta \mathrm{Z}$ mineral loss $(\mathrm{vol} \% \times \mu \mathrm{m})$ for the control and for the antibacterial composite side for 17 study participants (participants \#1 to $\# 17)$; in all cases, the $\Delta \mathrm{Z}$ mineral loss for the antibacterial composite side was lower than for the control side 
The study here used an in situ caries model, aiming to determine the extent of typical inner secondary caries lesions detected at cavity walls of restorations. The development of outer caries lesions was not evaluated. Actually, it was intentionally inhibited by covering the outer tooth/enamel slab surface of the test specimens with an acid-resistant nail varnish.

Secondary caries development has been evaluated by others using in situ models, introducing various gap size dimensions from 25 to $1025 \mu \mathrm{m}$ width [9,55-58], with no observed differences in mineral loss with different gap sizes [56] or findings of wider caries lesions with wider gap sizes $[57,58]$. These studies mainly utilized dentin models. The gap model used in this in situ study was fabricated in the laboratory in a bathtub-like acrylic mold with enamel as test site. The enamel sample surfaces were polished, highly likely enhancing initial lesion formation [50]. A defined and consistent gap, simulating a natural, potentially occurring gap between a filling and the restored enamel, was introduced using a thin matrix band insertion between the enamel slab and the composite. The thickness of the matrix bands utilized did not vary. In addition, incremental placing of the composite against the matrix band allowed a consistent width of the artificial gap. This allowed a comparison between the effect of the antimicrobial active test composite and the control composite on enamel demineralization creating a wall lesion as a typical secondary caries inner lesion due to the microbial plaque located in the artificial gap.

Lower partial dentures were chosen as carriers for the testing sites in this in situ study. While caries progression, as described above, would have been faster using upper palatal carriers, these palatal carriers could not be chosen, since the placement of the newly designed gap model required relatively thick acrylic flanges to recess them into the flanges and then allow for collecting of microbial plaque. Palatal placement of these thick gap models would have negatively changed the denture wearing comfort. Buccal flanges of the lower RPD as insertion areas did not negatively influence the wearing experiences for the participants. Consequently, participants were more compliant to the request of wearing the RPD day and night, to prevent drying out of the microbial plaque.

In their systematic review related to in situ studies, Hollanders and coworkers reported that to measure the lesion development, microradiography techniques (TMR or transversal wavelength-independent microradiography [TWIM]) were used in $36 \%$, and in $48 \%$, cross-sectional microhardness testing was used [50]. In this present study, all samples were prepared for cross-sectional microhardness testing to determine the mean relative mineral loss values delta $\mathrm{Z}$ $(\Delta Z)$ among groups by using previously verified and published techniques [59-61]. The cross-sectional microhardness testing revealed that the mineral loss on the control side using a non-antibacterial active control composite was significantly higher than the mineral loss on the side where the antibacterial active composite with the incorporated quaternary ammonium silica dioxide (QASi) particles was located. The mineral loss on the control side was roughly three times higher than on the test composite side ( $\Delta Z 774.2$ vs. $\Delta Z$ 234.9). In addition, for each individual participant, the mineral loss on the side harboring the new composite was lower than on the control side. Obviously, the new composite was able to show its antibacterial capacity.

To assure that differences between mineral loss on the test composite side versus the control composite side were not influenced by other factors, the composite itself, a mixedeffects linear regression model, was fitted for enamel mineral loss $\Delta \mathrm{Z}$. As expected, placement of the gap model with the antibacterial active group in the right or left denture flange was not associated with enamel mineral loss $\Delta \mathrm{Z}$. The gender of the participant had no influence either. Unexpectedly, one additional participant factor associated with greater demineralization was placement of the gap model with the antibacterial active group in the flange of a newer RPD, with a newer RPD defined as a partial denture delivered to the participant in the last 3 to 4 weeks before inserting the gap model. Newer denture base acrylic resins leach out substances like unreacted residual monomer [62-64], which are cytotoxic and potentially bactericidal. Consequently, the opposite behavior as the mixed-effect model indicated could be hypothesized, with lower demineralization of enamel slabs placed in newer denture flanges due to a theoretically additional bacteria killing by the released denture monomer. This seemed not to have happened.

Wearing the in situ model for a longer duration (29 days to 30 days) than a shorter duration ( 26 to 28 days) was the second factor associated with greater demineralization. This might seem as more logical, but nevertheless, the differences in wear time of at maximum 4 days appear very small. Overall, the magnitude of the difference in enamel demineralization observed for denture age and wearing time were much smaller than the observed difference due to the treatment assignment, control versus test material.

The anti-caries effect of resins modified by quaternary ammonium monomers has been demonstrated $[65,66]$ but leaching of monomers from acrylic resins is a common issue [62-64, 67]; thus, these antibacterial effects may be diminished over time. By placing composite fillings with incorporated quaternary ammonium silica dioxide (QASi), which does not leak out, the risk of mineral loss and thus recurrent decay will be significantly reduced over time. These surfacemodified nanoparticles are like other nanoparticle fillers permanently integrated into the composite matrix [22]. After 6 months of accelerating aging, the antibacterial activity of composites with QASi nanoparticles was not reduced [19]. Bacterial death after contact with these modified composites has been observed $[24,18]$. 
With regard to safety and potential cytotoxicity of the new composites, it can be stated that the Nobio Infinix composites with QASi nanoparticles received U.S. FDA clearance in 2019 , with additional clearance in 2020, allowing a manufacturer's claim that the Nobio Infinix antibacterial composites significantly reduce tooth demineralization. To achieve clearance, materials have to undergo all biocompatibility tests required for a class IIa device (externally communicating device) with permanent ( $>30$ days) contact with tissue, bone, and dentin, according to ISO 10993-1 and ISO 7405. Biocompatibility tests included in this case cytotoxicity, oral irritation, sensitization, pyrogenicity, genotoxicity, and acute systemic toxicity.

In terms of cytotoxicity, Nobio Infinix composites were tested for potential cytotoxic effects using an in vitro mammalian cell culture test. The cytotoxicity test scale ranges from scale 0 to 4 , with 0 being no cytotoxic reactivity and 4 being severe reactivity. The Nobio Infinix antibacterial composites showed scale 0 cytotoxicity, with no evidence of causing cell lysis reduction of cell growth (NAMSA, 6750 Wales Road, Northwood, OH 43619, unpublished data). Consequently, the Nobio Infinix composites met the FDA requirements for clearance.

Biocompatibility of these nanoparticles has been proven in vitro and in vivo [23]. Related to antimicrobial activities, agar diffusion tests (ADTs) may determine bactericidal effects of bactericidal components leaching out of materials [68]. Antibacterial in vitro tests for composites that do not contain leaching out components like QASi nanoparticles use for testing of bactericidal activity the methodology of direct contact tests (DCTs) [69, 70]. They are routinely performed for quality assurance of such composites. The bactericidal efficiency has been tested for Nobio Infinix composites on bacteria from whole saliva, on Streptococcus mutans and on Enterococcus faecalis. All direct contact in vitro tests showed an at least 6 times logarithmical reduction in bacterial viability. Actually, Nobio Infinix composites demonstrated complete growth inhibition of bacteria, when the bacteria came in contact with Nobio Infinix composites (unpublished data).

The physical properties of a composite seem not to be diminished by adding these modified nanoparticles [16, 22]. Consequently, this type of antibacterial active composites could be considered to be added to the Caries Management by Risk Assessment (CAMBRA) armamentarium [27, 28].

\section{Limitations of the study}

While sufficiently powered, the results of this relatively small study should be examined in additional populations. It is also unclear how the magnitude of differences in demineralization in this in situ model will translate to the incidence of secondary caries in actual restorations. It would be of interest to learn how a difference in gap width might influence the results and at what maximum gap width a reduction in demineralization using this antibacterial active composite might still occur. It is assumed that the gap width produced was consistent throughout the study, but variations and consequently slight differences in the demineralization effect due to gap sizes cannot completely be ruled out. An additional limitation of the study is that we have not evaluated the potential effects of the new composite on reducing demineralization in the location prone for formation of the outer caries lesion.

\section{Conclusions and clinical relevance}

The in situ clinical study showed that composites with QASi antibacterial particles significantly reduced demineralization in enamel adjacent to a $38-\mu \mathrm{m}$ artificial gap in an in situ gap model in comparison to a conventional composite, with mineral loss evaluated by crosssectional microhardness testing in the laboratory. In addition, in each single individual participant, the evaluated mineral loss in the enamel slabs was lower on the side with the test composite when compared with the side carrying the control composite. Consequently, composites with QASi nanoparticle technology have the potential to reduce the occurrence of secondary caries.

Acknowledgements We gratefully thank Dr. Richard Kinsel, UCSF School of Dentistry, for his invaluable help with writing the paper.

Funding This work is a Principal Investigator-Initiated Study and was funded by Nobio Ltd. (Kadima, Israel) through the University of California, San Francisco's Industry Contracts \& Grants Division.

Data availability At this point in time, the datasets used and/or analyzed during the study are available from the corresponding author on reasonable request.

\section{Declarations}

Ethics approval All procedures performed in this study involving human participants were in accordance with the ethical standards of the institutional and/or national research committee and with the 1964 Helsinki Declaration and its later amendments or comparable ethical standards.

Consent to participate Informed consent was obtained from all individual participants included in the study.

Consent to submit the manuscript and contribution Consent to submit has been received explicitly from all co-authors. All authors have contributed sufficiently to the scientific work and therefore share collective responsibility and accountability for the results. 
Conflict of interest The authors declare no conflict of interest.

\section{References}

1. Machiulskiene V, Campus G, Carvalho JC, Dige I, Ekstrand KR, Jablonski-Momeni A, Maltz M, Manton DJ, Martignon S, Martinez-Mier EA, Pitts NB, Schulte AG, Splieth CH, Tenuta LMA, Ferreira Zandona A, Nyvad B (2020) Terminology of dental caries and dental caries management: Consensus report of a workshop organized by ORCA and Cardiology Research Group of IADR. Caries Res 54(1):7-14. https://doi.org/10.1159/000503309

2. Mjor IA, Toffenetti F (2000) Secondary caries: a literature review with case reports. Quintessence Int 31(3):165-179

3. Mjor IA (2005) Clinical diagnosis of recurrent caries. J Am Dent Assoc 136(10):1426-1433

4. Kopperud SE, Tveit AB, Gaarden T, Sandvik L, Espelid I (2012) Longevity of posterior dental restorations and reasons for failure. Eur J Oral Sci 120(6):539-548. https://doi.org/10.1111/eos.12004

5. Maupome G, Sheiham A (1998) Criteria for restoration replacement and restoration life-span estimates in an educational environment. J Oral Rehabil 25(12):896-901

6. Ersen KA, Gurbuz O, Ozcan M (2020) Evaluation of polymerization shrinkage of bulk-fill resin composites using microcomputed tomography. Clin Oral Investig 24(5):1687-1693. https://oi.org/ 10.1007/s00784-019-03025-5

7. Kruly PC, Giannini M, Pascotto RC, Tokubo LM, Suga USG, Marques ACR, Terada RSS (2018) Meta-analysis of the clinical behavior of posterior direct resin restorations: low polymerization shrinkage resin in comparison to methacrylate composite resin. PLoS One 13(2):e0191942. https://doi.org/10.1371/journal.pone. 0191942

8. Khvostenko D, Hilton TJ, Ferracane JL, Mitchell JC, Kruzic JJ (2016) Bioactive glass fillers reduce bacterial penetration into marginal gaps for composite restorations. Dent Mater 32(1):73-81. https://doi.org/10.1016/j.dental.2015.10.007

9. Ferracane JL (2017) Models of caries formation around dental composite restorations. J Dent Res 96(4):364-371. https://doi.org/10. $1177 / 0022034516683395$

10. Benelli E, Serra M, Rodrigues AJ, Cury J (1993) In situ anticariogenic potential of glass ionomer cement. Caries Res 27(4):280-284

11. Gorton J, Featherstone JD (2003) In vivo inhibition of demineralization around orthodontic brackets. Am J Orthod Dentofacial Orthop 123(1):10-14

12. Hara AT, Turssi CP, Ando M, Gonzalez-Cabezas C, Zero DT, Rodrigues AL Jr, Serra MC, Cury JA (2006) Influence of fluoride-releasing restorative material on root dentine secondary caries in situ. Caries Res 40(5):435-439. https://doi.org/10.1159/ 000094290

13. Dijkman G, Arends J (1992) Secondary caries in situ around fluoride-releasing light-curing composites: a quantitative model investigation on four materials with a fluoride content between 0 and 26 vol. Caries Res 26(5):351-357

14. Chatzistavrou X, Fenno JC, Faulk D, Badylak S, Kasuga T, Boccaccini AR, Papagerakis P (2014) Fabrication and characterization of bioactive and antibacterial composites for dental applications. Acta Biomater 10(8):3723-3732. https://doi.org/10.1016/j. actbio.2014.04.030

15. Chatzistavrou X, Lefkelidou A, Papadopoulou L, Pavlidou E, Paraskevopoulos KM, Fenno JC, Flannagan S, Gonzalez-Cabezas C, Kotsanos N, Papagerakis P (2018) Bactericidal and bioactive dental composites. Front Physiol 9:103. https://doi.org/10.3389/ fphys.2018.00103
16. Beyth N, Yudovin-Farber I, Bahir R, Domb AJ, Weiss EI (2006) Antibacterial activity of dental composites containing quaternary ammonium polyethylenimine nanoparticles against Streptococcus mutans. Biomaterials 27(21):3995-4002. https://doi.org/10.1016/j. biomaterials.2006.03.003

17. Beyth N, Houri-Haddad Y, Baraness-Hadar L, Yudovin-Farber I, Domb AJ, Weiss EI (2008) Surface antimicrobial activity and biocompatibility of incorporated polyethylenimine nanoparticles. Biomaterials 29(31):4157-4163. https://doi.org/10.1016/j. biomaterials.2008.07.003

18. Beyth N, Yudovin-Farber I, Perez-Davidi M, Domb AJ, Weiss EI (2010) Polyethylenimine nanoparticles incorporated into resin composite cause cell death and trigger biofilm stress in vivo. Proc Natl Acad Sci U S A 107(51):22038-22043. https://doi.org/10.1073/ pnas. 1010341107

19. Beyth N, Yudovin-Fearber I, Domb AJ, Weiss EI (2010) Longterm antibacterial surface properties of composite resin incorporating polyethylenimine nanoparticles. Quintessence Int 41(10):827835

20. Chatzistavrou X, Velamakanni S, DiRenzo K, Lefkelidou A, Fenno JC, Kasuga T, Boccaccini AR, Papagerakis P (2015) Designing dental composites with bioactive and bactericidal properties. Mater Sci Eng C Mater Biol Appl 52:267-272. https://doi.org/10. 1016/j.msec.2015.03.062

21. Gou YP, Meghil MM, Pucci CR, Breschi L, Pashley DH, Cutler CW, Niu LN, Li JY, Tay FR (2018) Optimizing resin-dentin bond stability using a bioactive adhesive with concomitant antibacterial properties and anti-proteolytic activities. Acta Biomater. https://doi. org/10.1016/j.actbio.2018.06.008

22. Zaltsman N, Ionescu AC, Weiss EI, Brambilla E, Beyth S, Beyth N (2017) Surface-modified nanoparticles as anti-biofilm filler for dental polymers. PLoS One 12(12):e0189397. https://doi.org/10.1371/ journal.pone. 0189397

23. Atar-Froyman L, Sharon A, Weiss EI, Houri-Haddad Y, KeslerShvero D, Domb AJ, Pilo R, Beyth N (2015) Anti-biofilm properties of wound dressing incorporating nonrelease polycationic antimicrobials. Biomaterials 46:141-148. https://doi.org/10.1016/j. biomaterials.2014.12.047

24. Shvero DK, Zatlsman N, Hazan R, Weiss EI, Beyth N (2015) Characterisation of the antibacterial effect of polyethylenimine nanoparticles in relation to particle distribution in resin composite. J Dent 43(2):287-294. https://doi.org/10.1016/j.jdent.2014.05.003

25. Beyth S, Polak D, Milgrom C, Weiss EI, Matanis S, Beyth N (2014) Antibacterial activity of bone cement containing quaternary ammonium polyethylenimine nanoparticles. J Antimicrob Chemother 69(3):854-855. https://doi.org/10.1093/jac/dkt441

26. Featherstone JD, ten Cate JM, Shariati M, Arends J (1983) Comparison of artificial caries-like lesions by quantitative microradiography and microhardness profiles. Caries Res 17(5):385-391

27. Featherstone JDB, Alston P, Chaffee BW, Rechmann P (2019) Caries Management by Risk Assessment (CAMBRA): an update for use in clinical practice for patients aged 6 through adult. J Calif Dent Assoc 47(1):25-36

28. Rechmann P, Chaffee BW, Rechmann BMT, Featherstone JDB (2018) Changes in caries risk in a practice-based randomized controlled trial. Adv Dent Res 29(1):15-23. https://doi.org/10.1177/ 0022034517737022

29. Clasen A, Ogaard B (1999) Experimental intra-oral caries models in fluoride research. Acta Odontol Scand 57(6):334-341

30. Zero D (1995) In situ caries models. Adv Dent Res 9(3):214-230

31. Stookey G, Schemehorn B, Cheetham B, Wood G, Walton G (1985) In situ fluoride uptake from fluoride dentifrices by carious enamel. J Dent Res 64(6):900-903

32. Raven S, Schafer F, Duckworth R, Gilbert R, Parr T (1991) Comparison between evaluation methods for the anti-caries 
efficacy of monofluorophosphate-containing dentifrices. Caries Res 25(2):130-137

33. Stephen K, Damato F, Strang R (1992) An in situ enamel section model for assessment of enamel re/demineralization potential. $\mathrm{J}$ Dent Res 71 Spec No:856-859

34. Mellberg J, Petrou I, Grote N (1992) A study of the ability of an in situ remineralization model to differentiate between the effects of two fluoride dentifrices that produced significantly different clinical caries results. J Dent Res 71(5):1169-1172

35. Gaffar A, Blake-Haskins J, Mellberg J (1993) In vivo studies with a dicalcium phosphate dihydrate/MFP system for caries prevention. Int Dent J 43(1 Suppl 1):81-88

36. Wefel J, Jensen M, Triolo P, Faller R, Hogan M, Bowman W (1995) De/remineralization from sodium fluoride dentifrices. Am J Dent 8(4):217-220

37. Wefel JS, Stanford CM, Ament DK, Hogan MM, Harless JD, Pfarrer AM, Ramsey LL, Leusch MS, Biesbrock AR (2002) In situ evaluation of sodium hexametaphosphate-containing dentifrices. Caries Res 36(2):122-128

38. Chow L, Takagi S, Carey C, Sieck B (2000) Remineralization effects of a two-solution fluoride mouthrinse: an in situ study. J Dent Res 79(4):991-995

39. van Strijp A, van Steenbergen T, ten Cate J (1997) Effects of chlorhexidine on the bacterial colonization and degradation of dentin and completely demineralized dentin in situ. Eur J Oral Sci 105(1):2735

40. Huizinga E, Arends J (1991) The effect of an antimicrobial releasing varnish on root demineralisation in situ. The influence of the demineralisation period. J Biol Buccale 19(1):29-33

41. Ogaard B, Rolla G, Ruben J, Arends J (1990) Relative cariostatic effects of $\mathrm{KOH}$-soluble and $\mathrm{KOH}$-insoluble fluoride in situ. J Dent Res 69(8):1505-1507

42. Bottenberg P, Cleymaet R, Rohrkasten K, Lampert F (2000) Microhardness changes in surface enamel after application of bioadhesive fluoride tablets in situ. Clin Oral Investig 4(3):153-156

43. Doherty UB, Benson PE, Higham SM (2002) Fluoride-releasing elastomeric ligatures assessed with the in situ caries model. Eur J Orthod 24(4):371-378

44. Cai F, Shen P, Morgan M, Reynolds E (2003) Remineralization of enamel subsurface lesions in situ by sugar-free lozenges containing casein phosphopeptide-amorphous calcium phosphate. Aust Dent J 48(4):240-243

45. Jensen OE, Billings RJ, Featherstone JD (1990) Clinical evaluation of Fluoroshield pit and fissure sealant. Clin Prev Dent 12(4):24-27

46. Featherstone J, Zero D (1992) An in situ model for simultaneous assessment of inhibition of demineralization and enhancement of remineralization. J Dent Res 71 Spec No:804-810

47. Ogaard B, Rolla G (1992) The in vivo orthodontic banding model for vital teeth and the in situ orthodontic banding model for hardtissue slabs. J Dent Res 71 Spec No:832-835

48. Benson P, Pender N, Higham S (1999) An in situ caries model to study demineralisation during fixed orthodontics. Clin Orthod Res 2(3):143-153

49. Dunipace A, Hall A, Kelly S, Beiswanger A, Fischer G, Lukantsova L, Eckert G, Stookey G (1997) An in situ interproximal model for studying the effect of fluoride on enamel. Caries Res 31(1):60-70

50. Hollanders ACC, Kuper NK, Maske TT, Huysmans M (2018) Secondary caries in situ models: a systematic review. Caries Res 52(6):454-462. https://doi.org/10.1159/000487200

51. Hals E, Andreassen BH, Bie T (1974) Histopathology of natural caries around silver amalgam fillings. Caries Res 8(4):343-358. https://doi.org/10.1159/000260123
52. Hals E, Nernaes A (1971) Histopathology of in vitro caries developing around silver amalgam fillings. Caries Res 5(1):58-77. https://doi.org/10.1159/000259733

53. Fontana M, Dunipace AJ, Gregory RL, Noblitt TW, Li Y, Park KK, Stookey GK (1996) An in vitro microbial model for studying secondary caries formation. Caries Res 30(2):112-118. https://doi.org/ $10.1159 / 000262146$

54. Diercke K, Lussi A, Kersten T, Seemann R (2009) Isolated development of inner (wall) caries like lesions in a bacterial-based in vitro model. Clin Oral Investig 13(4):439-444. https://doi.org/ 10.1007/s00784-009-0250-z

55. Kuper NK, Montagner AF, van de Sande FH, Bronkhorst EM, Opdam NJ, Huysmans MC (2015) Secondary caries development in in situ gaps next to composite and amalgam. Caries Res 49 (5): 557-563. https://doi.org/10.1159/000438728

56. Kuper NK, Opdam NJ, Ruben JL, de Soet JJ, Cenci MS, Bronkhorst EM, Huysmans MC (2014) Gap size and wall lesion development next to composite. J Dent Res 93 (7 Suppl):108S113S. https://doi.org/10.1177/0022034514534262

57. Maske TT, Hollanders ACC, Kuper NK, Bronkhorst EM, Cenci MS, Huysmans M (2019) A threshold gap size for in situ secondary caries lesion development. J Dent 80:36-40. https://doi.org/10. 1016/j.jdent.2018.10.014

58. Nassar HM, Gonzalez-Cabezas C (2011) Effect of gap geometry on secondary caries wall lesion development. Caries Res 45(4):346352. https://doi.org/10.1159/000329384

59. Featherstone JD, Barrett-Vespone NA, Fried D, Kantorowitz Z, Seka W (1998) CO2 laser inhibitor of artificial caries-like lesion progression in dental enamel. J Dent Res 77(6):1397-1403

60. Featherstone JD, Glena R, Shariati M, Shields CP (1990) Dependence of in vitro demineralization of apatite and remineralization of dental enamel on fluoride concentration. J Dent Res 69 Spec No:620-625; discussion 634-626

61. Toda S, Featherstone JD (2008) Effects of fluoride dentifrices on enamel lesion formation. J Dent Res 87(3):224-227

62. Chaves CA, Machado AL, Vergani CE, de Souza RF, Giampaolo ET (2012) Cytotoxicity of denture base and hard chairside reline materials: a systematic review. J Prosthet Dent 107(2):114-127. https://doi.org/10.1016/S0022-3913(12)60037-7

63. Ica RB, Ozturk F, Ates B, Malkoc MA, Kelestemur U (2014) Level of residual monomer released from orthodontic acrylic materials. Angle Orthod 84(5):862-867. https://doi.org/10.2319/060713-435.

64. Nik TH, Shahroudi AS, Eraghihzadeh Z, Aghajani F (2014) Comparison of residual monomer loss from cold-cure orthodontic acrylic resins processed by different polymerization techniques. J Orthod 41(1):30-37. https://doi.org/10.1179/1465313313Y. 0000000078

65. Yu J, Huang X, Zhou X, Han Q, Zhou W, Liang J, Xu HHK, Ren B, Peng X, Weir MD, Li M, Cheng L (2020) Anti-caries effect of resin infiltrant modified by quaternary ammonium monomers. J Dent 97:103355. https://doi.org/10.1016/j.jdent.2020.103355

66. Maia AC, Mangabeira A, Vieira R, Neves AA, Lopes RT, Pires TM, Viana GM, Cabral LM, Cavalcante LM, Portela MB (2019) Experimental composites containing quaternary ammonium methacrylates reduce demineralization at enamel-restoration margins after cariogenic challenge. Dent Mater 35(8):e175-e183. https://doi. org/10.1016/j.dental.2019.05.02

67. Vidal ML, Rego GF, Viana GM, Cabral LM, Souza JPB, Silikas N, Schneider LF, Cavalcante LM (2018) Physical and chemical properties of model composites containing quaternary ammonium methacrylates. Dent Mater 34(1):143-151. https://doi.org/10.1016/j. dental.2017.09.020 
68. Tobias RS (1988) Antibacterial properties of dental restorative materials: a review. Int Endod J 21(2):155-160. https://doi.org/10. 1111/j.1365-2591.1988.tb00969.x

69. Weiss EI, Shalhav M, Fuss Z (1996) Assessment of antibacterial activity of endodontic sealers by a direct contact test. Endod Dent Traumatol 12(4):179-184. https://doi.org/10.1111/j.1600-9657. 1996.tb00511.x

70. Koruyucu M, Topcuoglu N, Tuna EB, Ozel S, Gencay K, Kulekci G, Seymen F (2015) An assessment of antibacterial activity of three pulp capping materials on Enterococcus faecalis by a direct contact test: an in vitro study. Eur J Dent 9(2):240-245. https://doi.org/10. 4103/1305-7456.156837

Publisher's note Springer Nature remains neutral with regard to jurisdictional claims in published maps and institutional affiliations. 